Article

\title{
Environmental Sustainability Assessment of Horticultural Systems: A Multi-Criteria Evaluation Approach Applied in a Case Study in Mediterranean Conditions
}

\author{
Francesco Montemurro ${ }^{1,2}$ (1) , Alessandro Persiani ${ }^{1}$ and Mariangela Diacono ${ }^{1, *}$ (1) \\ 1 Council for Agricultural Research and Economics-Research Centre for Agriculture and Environment, \\ CREA-AA, Via Celso Ulpiani 5, 70125 Bari, Italy; francesco.montemurro@crea.gov.it (F.M.); \\ alessandro.persiani@crea.gov.it (A.P.) \\ 2 Council for Agricultural Research and Economics-Research Centre for Vegetable and Ornamental Crops, \\ CREA-OF, Via Salaria 1, 63030 Monsampolo del Tronto (AP), Italy \\ * Correspondence: mariangela.diacono@crea.gov.it; Tel.: +39-080-5475052
}

Received: 3 May 2018; Accepted: 20 June 2018; Published: 22 June 2018

check for updates

\begin{abstract}
An increasing interest and sensitivity of consumers and public opinion toward high-quality food products obtained with environmentally-friendly production methods has recently been detected. To this end, one of the key roles could be played by an environmental evaluation of the crop production. This research was performed to test a new multi-attribute decision model (DEXi-met) that is able to estimate the environmental sustainability of different agronomic practices in horticultural rotations. The model was used at the cropping system level on the basis of data from a long-term experiment in organic horticulture. It was tested on different cropping managements under climate change conditions. The DEXi-met mixed model (qualitative and qualitative basic attributes) generated four aggregated attributes to assess sustainability indicators (production capacity, soil, water and resources preservation, and biodiversity conservation) and the overall environmental sustainability. The model validation indicated that the introduction of agro-ecological services crops can increase the environmental sustainability of an organic cropping systems by promoting the whole soil-plant system equilibrium. The application of this tool could help maximize the efficient use of agronomical practices and quantify their environmental sustainability. DEXi-met could help agricultural advisors and policymakers schedule their decisions to find the right compromise between crop yield increase and the impact of agricultural activities.
\end{abstract}

Keywords: multi-attribute model; DEXi-met; qualitative and quantitative attributes; environmental sustainability; agronomical practices; organic horticulture; climate change

\section{Introduction}

The Intergovernmental Panel on Climate Change (IPCC) defines "climate change" as the statistically significant variations in climate that persist for an extended period, typically a decade or longer [1]. This change also includes the increase in both the frequency and magnitude of extreme weather events, and in particular the rise in global mean surface temperature, storms, droughts, etc. It has been reported that global greenhouse gas emissions (which contribute to climate change) increased by 70\% between 1970-2004 [1,2]. Agriculture is one of the sectors that significantly influence the climate, since agricultural practices and livestock activities are responsible for about 20 and $5-10 \%$, respectively, of the yearly growth in anthropogenic greenhouse emissions [3]. 
Conversely, it has been demonstrated that sustainable agriculture, which is capable of maintaining its productivity while preserving ecosystems and non-renewable resources [4], has great potential to mitigate climate change in comparison with conventional farm management. In particular, the IPCC [5] pointed out that a great amount of greenhouse emissions could be reduced through agriculture, when sustainable agricultural practices are adopted. On this matter, climate-friendly agricultural technologies and practices are easily available and cost-effective with multiple benefits. In particular, in the low-input and organic farming systems, the introduction of crop rotations, agro-ecological service crops (ASC), and their proper termination (e.g., green manuring, or flattening by a roller crimper-Figure 1a), are some common practices. More specifically, the latter technique reduces tillage and provides beneficial services to the agro-ecosystems, such as contributing to weed, pest, and disease management, nitrate leaching reduction, and improving soil water retention and crop tolerance to drought [6].

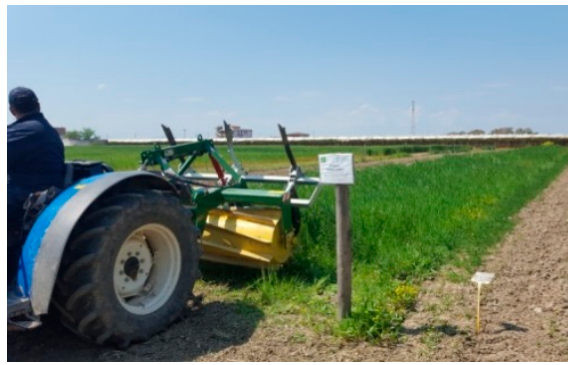

(a)

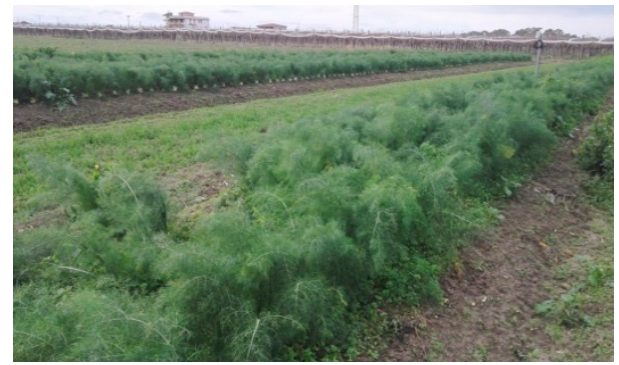

(b)

Figure 1. (a) Agro-ecological service crops management: termination by a roller crimper; (b) fennels cultivated in the raised bed and agro-ecological service crops in the flat areas (or strips). Both photos refer to the long-term field experiment "MITIORG", which has been used to develop and test our qualitative multi-attribute decision model, DEXi-met, (research farm of the CREA- Research Centre for Agriculture and Environment, in southern Italy).

The adoption of these practices is in line with the concept of sustainable agriculture. Therefore, agronomists, farmers, and researchers should seek to design agricultural systems that are environmentally sound, resource-conserving, economically viable, socially supportive, and adapted to a climate change context. At the same time, it is important to develop more tools for agricultural sustainability assessment to promote the concept of sustainable agricultural systems, since sustainability principles might be incorporated into agricultural policy planning and decision-making [7]. Within sustainability overall (environmental, economic, and social), the environmental aspect has received increased attention from both consumers and public opinion. Therefore, the purpose of the agricultural sustainability assessment is to help decision-makers in determining which actions should or should not be taken in account, in an attempt to move toward sustainable agriculture [8], with particular attention to environmental sustainability.

There are several methodologies to assess the impact of agriculture on the environment, addressing different dimensions and objectives of sustainability $[9,10]$. One of the methodologies that can be adopted to evaluate the environmental sustainability of the agricultural practices is to assess the agronomic procedures as a typical decision-making problem, which could be managed by multi-criteria decision-aid methods [11,12]. These methods are generally used to assess decision alternatives [13] and/or different agricultural practices [14]. In a comparative review of the main types of multi-criteria decision-aid methods, Sadok et al. [15] suggested that decision rule-based methods managing qualitative input information are particularly relevant to handle the multi-dimensional constraints of the entire sustainability assessment. The use of the above-described methodology was considered crucial for evaluating the overall performance of agricultural productive systems, as well as steering the stakeholders toward the best crop management alternatives. 
There are several models that assess the different dimensions of agricultural sustainability (e.g., environmental, economical, and social); due to the base knowledge available, environmental sustainability is more commonly defined. However, there is still a lack of knowledge regarding the evaluation of environmental performances with multi-criteria approaches for organic horticultural crop cultivations, particularly when new agronomical practices are adopted that are linked with the mitigation of climate change. Thus, the aims of the present research were: (i) to create a new qualitative multi-attribute decision model that is able to easily estimate the ex-post environmental sustainability in horticultural crop rotations, at the cropping system scale, particularly under climate change conditions; (ii) to test the model by the estimation and comparison of the environmental impacts of crop management practices and, in particular, assess the effect of the agro-ecological service crops on the environmental sustainability of organic horticultural systems. The new model was developed on the basis of data coming from a long-term experiment in organic horticulture (Figure 1b) that has been conceived and designed to adapt cultivations to climate change in the Mediterranean environment.

\section{Materials and Methods}

In the current study, a model was developed that was based both on a computer program for decision-making (DEXi) and on long-term research concerning horticultural crop rotations.

\subsection{DEXi Software Description}

DEXi is a free and publicly available computer program for multi-attribute decision-making, which evaluates options according to several, possibly conflicting objectives [16]. A multi-attribute model is a hierarchical structure that allows decomposing the decision problem into sub-problems, which are less complex and possibly easier to solve than the complete problem. Therefore, DEXi supports the interactive development of qualitative multi-attribute decision models and their application for the evaluation and analysis of an options set, in order to satisfy the goals of decision makers.

DEXi was conceived in 1999, and its methodology has a long history of scientific, technical, and practical contributions $[13,14,17,18]$, including the evaluation of the entire agricultural sustainability and decision making. The program differs from most conventional multi-attribute hierarchical decision modeling tools, since it uses symbolic qualitative attributes instead of numeric quantitative ones [13]. The set of attributes is organized in a tree-like structure, pointing out the hierarchical nature of DEXi (Figure 2).

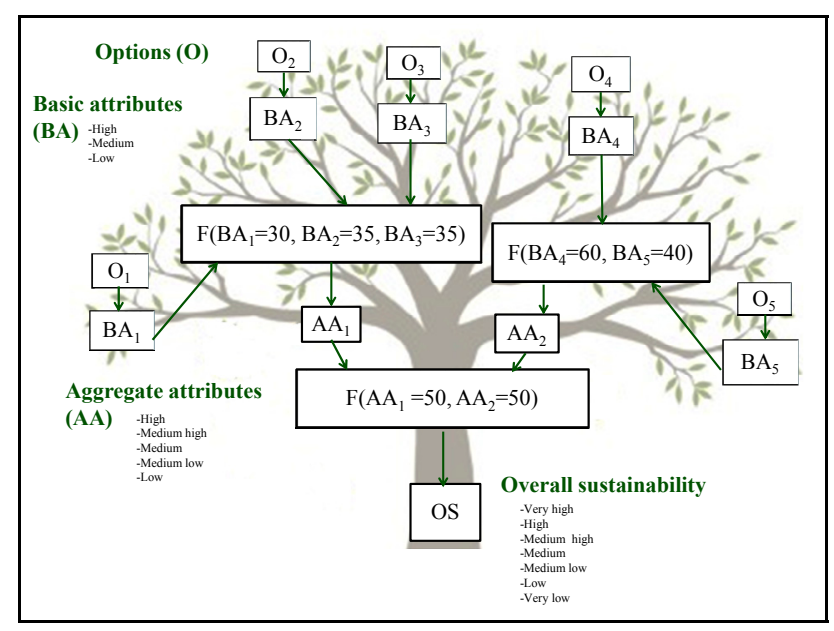

Figure 2. Example of a typical multi-attribute DEXi model, indicating basic attributes (BA), options $(\mathrm{O})$, aggregate attributes (AA), utility function (F), and overall sustainability (OS). 
In this structure, the "leaves" of the tree are the basic measurable attributes, and they represent the decision sub-problems. The basic attributes are also the inputs of the model in which it is possible to assess each option [18]. The options are described by the values of the basic attributes (indicators). Each attribute can be decomposed into one or more descendant attributes (called aggregate attributes), which appear one level below that attribute in the tree, representing option evaluations. The indicators can be both qualitative and quantitative. The quantitative indicators are based on measurements by a specific team of decision analysts and experts, or data obtained from technical and/or scientific references. In any case, to translate quantitative variables into qualitative ones, there is a need to define threshold values. By contrast, the qualitative attributes do not need any transformation.

The scale represents a set of values that can be assigned to an attribute. In DEXi, scales are qualitative and discrete, and consist of a set of words such as: 'high, medium, low', 'excellent, acceptable, unacceptable', etc. The scales can be either ordered (increasing/decreasing) or unordered. In this last case a collection of values is generally obtained, and their relation is unknown or undefined. Conversely, the values of an ordered scale are arranged according to their contribution to the quality of options [16]. To define the aggregation aspect of option evaluation, there are other components of multi-attribute models called utility functions. In DEXi, the utility aggregation functions are defined by the "if-then" decision rules, e.g., if BA1 is "medium high" and if BA2 and BA3 are "high", then AA1 is "high" (Figure 2). Each utility function can be filled in manually or by using an approach assigning a weight to each attribute [13]. These weights are numbers that are normalized to the sum or maximum of 100 , which define the contribution of the corresponding attribute to the final evaluation. Then, they are used in decision analysis to model the importance of the attributes.

In DEXi, the structures are dynamic, in that changing the qualitative value of a given attribute and/or modifying a few decision rules can have an immediate effect on the overall assessment [15].

\subsection{Study Site and Experimental Device}

To develop the new multi-criteria decision model, the study has been conducted in the MITIORG (Long-term climatic change adaptation in organic farming: synergistic combination of hydraulic arrangement, crop rotations, agro-ecological service crops, and agronomic techniques) field experiment, which is located in the research farm of the Research Centre for Agriculture and Environment, CREA-AA, at Metaponto (MT) in southern Italy (lat. $40^{\circ} 24^{\prime} \mathrm{N}$; long. $16^{\circ} 48^{\prime} \mathrm{E}, 8 \mathrm{~m}$ above the sea level). The MITIORG long-term experimental device was conceived starting from the knowledge derived by previous studies on the field application of agro-ecological strategies under climate change conditions [19]. These strategies have been used to adapt cultivations to extreme rainfall events during autumn and winter periods, which greatly influenced vegetable crops productivity in the study area in recent decades. The field experiment was designed through combining a set of functionally integrated techniques (conceptually identified as "layers"), namely: (i) soil surface shaping; (ii) crop rotations, and in particular the succession of vegetable cash crops and agro-ecological service crops (ASC) over several years; (iii) ASC introduction; (iv) ASC termination techniques; and (v) organic fertilization.

The base layer is the soil hydraulic arrangement by means of soil surface shaping as a kind of (minimum tilled) ridge system. The vegetable crops are cultivated both above the raised bed (ridges $2.5-\mathrm{m}$ wide) and in the $2.5-\mathrm{m}$ flat areas (or strips) between them. Crop rotation (the second conceptual layer) is designed to avoid cash crop cultivation during the winter-rainy period of the year in the flat strips, which can be waterlogged in the case of heavy rain and/or temporary flooding. The third conceptual layer uses cover crops to prevent soil erosion and provide $\mathrm{N}$ to the system via biological fixation. In fact, in the flat soil strips, pure ASC or mixtures of different proportions of legume and non-legume crops, which are potentially resistant to temporary water excess, are cultivated during the winter-rainy period between two consecutive spring-summer cash crops. These break ASC are terminated with a roller crimper before the transplanting of cash crops [6]. The last layer consists of an organic fertilization strategy, which is implemented using commercial and/or innovative fertilizers 
and amendments, i.e., anaerobic digestates, with the aim of maintaining or increasing long-term soil organic matter and fertility.

\subsection{Experimental Setup, Treatments, and Measurements}

Within the MITIORG research, the field trial carried out in the flat strips during the 2016 season was considered as a basis to design the qualitative multi-attribute decision model. More in detail, the cash crop sequence that was analyzed was zucchini, followed by lettuce. The cover crops treatment was a mixture of legume, grasses, and brassicas, and was cultivated in the winter period and terminated by flattening with a roller crimper (RC-ASC). This treatment was compared to a NO-ASC control. The obtained thick mulch layer in RC-ASC remained in place, covering the soil surface and, after zucchini harvest, it was incorporated in the soil by rotary tiller (about 15-cm depth). The organic fertilization was the same in all of the treatments, i.e., a composted anaerobic digestate. This fertilizer was applied a few days and 10 days before ASC termination and transplanting for zucchini and lettuce, respectively. In particular, $120 \mathrm{~kg} \mathrm{~N} \mathrm{ha}^{-1}$ and $100 \mathrm{~kg} \mathrm{~N} \mathrm{ha}^{-1}$ for zucchini and lettuce, respectively, were distributed for the NO-ASC control. By contrast, to account for the potential contribution of ASC for N, the fertilization applied on RC-ASC was $100 \mathrm{~kg}$ for both zucchini and lettuce, considering the contribution of $20 \mathrm{~kg} \mathrm{~N} \mathrm{ha}^{-1}$ by legume cover. Each elementary plot resulted in a $30 \mathrm{~m}^{2}$ area. The zucchini crop was manually transplanted on 26 April 2016, and it was harvested three times at the crops commercial maturity, from 6 June to 13 July. Lettuce was transplanted on 29 July and harvested on 28 September, and five randomly selected plants in each plot were collected at harvest, to determine yield $\left(\mathrm{t} \mathrm{ha}{ }^{-1}\right)$. Similarly, the zucchini marketable yield $\left(\mathrm{t} \mathrm{ha}^{-1}\right)$ was obtained from five randomly selected plants in each plot.

\section{Results and Discussion}

\subsection{Developing a New Qualitative Multi-Criteria Decision Model: "DEXi-Met" Model}

The aim that led us to develop a new DEXi model was to evaluate the environmental sustainability of different management practices in horticulture, particularly for organic vegetable production. We decided to operate at the cropping system level, with the idea that the model might be used by the agricultural advisors, researchers, or policymakers, for ex-post overall environmental sustainability assessment. This was because the interest of both consumers and public opinion for the evaluation of the environmental aspect has been considerably increased through the last years. Furthermore, among the tested management practices our attention have been focused on the effect of the introduction of ASC in organic horticultural systems. As a consequence, the DEXi-met mainly focuses on organic agriculture evaluation. Moreover, in our model, we consider a cropping system and not only a single cash crop, in order to have a broader idea of the environmental sustainability of the system.

To define a DEXi model, it is necessary to firstly identify the input attributes, and then to specify the hierarchical structure of the model and define the qualitative measurement scales of the attributes. Then, the aggregation rules should be defined. Usually, DEXi models are developed in collaboration between decision analysts and experts in the specific field of interest, as suggested by Taškova et al. [20]. By following this suggestion, the development and design of the new model (from now on named "DEXi-met") and its first application were carried out involving both decision analysts and experts (i.e., researchers, agronomists, and farmers). The decision rules were not specified explicitly in tabular form, but rather implicitly by specifying the weight of input attributes. As a consequence, in our DEXi-met model, the decision rules in tabular form are derived from the weights. Following the general indications of the DEXi-model, we defined the decision procedures (qualitative measurement scales, aggregation rules, etc.), producing a specific, complex, and complete excel spreadsheet. Furthermore, the team of decision analysts and experts in our field of interest decided the single value of the specific weight for each input attribute. 
Different authors widely studied and examined the indicators used in the evaluation of sustainability $[13,15,21]$. On the basis of these indicators, a group of 30 basic attributes were selected to define the environmental sustainability of the cultivation process. To shape DEXi-met, these 30 basic attributes were created in an excel spreadsheet, as a result of the specific definition of qualitative scale classes and quantitative values. For example, the qualitative class "crop rotation" was defined as follows: (i) "low" when there was not any rotation, and the crops were decided following the market trends; (ii) "medium" when a rotation was performed and the same crop did not return to the same field before two crop cycles; and (iii) "high" when in the cultivation sequence, the crop did not return to the same surface before four years, with the crop species being chosen according to an agro-ecological approach. Conversely, the quantitative values were a result of the specific field experiment (e.g., "N balance", "production quantity", "water consumption"), and they were evaluated by the group of decision analysts and experts. Among the 30 basic attributes, 11 of them were generated by a satellite tree (Table 1); again, they were studied, evaluated, proposed, and applied in the DEXi-met by the team of experts.

Each satellite tree is a new independent subject that is used to fill and define a basic attribute. As a normal decision tree, the inputs of the satellite trees were filled either with the qualitative and/or quantitative variables. Therefore, at the end, the basic attributes generated in the DEXi-met model could be defined as "mixed", since the model included both qualitative and quantitative items.

To summarize, in our model, a share of attributes was generated by the decision of the analysts and experts for this specific model. This step was done keeping in mind the main goal of the qualitative multi-attribute decision tool, which was to develop a model to understand the environmental sustainability of different management procedures in organic vegetable production at the cropping system level. The other attributes were obtained from the literature, in particular from the MASC and DEXi-Biort models [15,21].

In Figure 3, the general DEXi-met model structure is shown in this model, unlike the other models such as MASC [15], the social and economic dimensions are not directly included and spelled out in the model. Nevertheless the economical aspect of the sustainability is partially incorporated indirectly in the nodal aggregate attribute "production capacity" (production quantity and production quality attributes). The social sustainability was not considered in this model, since we did not include any attributes. The other three nodal attributes are focused on environmental sustainability, and for this reason, it is quite clear that the DEXi-met model was conceived and designed to give a greater importance and detail to the environmental dimension of sustainability. Within each different attribute level, both the weights utilized in the aggregation function and the scale of values are reported (Figure 3).

Except for soil treatments and the specific variability and flora conservation attributes, the percentage of the weight of all of the basic and aggregate attributes were indicated by the group of decision analysts and experts as a unique value. The scale classes ranged from two to four values in the basic attribute (for example: low, medium, high) and from two to seven values when they were utilized for the overall sustainability (very low, low, medium low, medium, medium high, high, very high). In accordance with Bohanec et al.'s [22] suggestions, this procedure was adopted to avoid the "combinatory explosion", since it is important to not associate too many criteria with too many qualitative classes. On the other hand, for the most aggregated attribute of environmental sustainability, more classes were used to better differentiate the outcomes. In agreement with the findings of Craheix et al. [13], the total number of attributes utilized in DEXi-met (i.e., 49 as the sum of basic, aggregate, and overall attributes) can be enough to adequately represent the diversity of objectives in the evaluated system. At the same time, this number is not too large to generate unnecessary complications when using the model and to reduce its ability to distinguish differences between systems. 
Table 1. Summary of the different knowledge sources used as input attributes in the DEXi-met model. Input attributes name, methodology used to calculate/estimate the input attributes/typology, and references (MASC $=[15]$; DEXi-Biort $=[21] ;$ new $=$ new attributes) in the columns.

\begin{tabular}{|c|c|c|c|}
\hline & Attributes & Calculation Methods/Typology & References \\
\hline 1 & Insect pests and diseases & satellite tree & MASC \\
\hline 2 & Weeds & satellite tree & MASC \\
\hline 3 & Soil structure & satellite tree & MASC \\
\hline 4 & $\mathrm{P}$ and $\mathrm{K}$ fertility & satellite tree & MASC \\
\hline 5 & Acido basic balance & satellite tree & MASC \\
\hline 6 & $\mathrm{~N}$ balance & $\mathrm{N}$ input/N output-quantitative & New \\
\hline 7 & Production quantity & marketable yield $(\mathrm{Kg})$ - quantitative & New \\
\hline 8 & Production quality & nitrates- dry matter- ${ }^{\circ}$ brix/fruit size- quantitative & New \\
\hline 9 & Water consumption & water utilization $\left(\mathrm{m}^{3}\right)$ - quantitative & New \\
\hline 10 & Groundwater utilization & $(\%)$-quantitative & DEXi-Biort \\
\hline 11 & Irrigation technology & -qualitative & DEXi-Biort \\
\hline 12 & Tillage diversification & -qualitative & DEXi-Biort \\
\hline 13 & Tillage typology and depth & -qualitative & DEXi-Biort \\
\hline 14 & Soil erosion control & satellite tree & MASC \\
\hline 15 & Organic matter balance & $C$ input/C output $\times$ isoumic coefficient-quantitative & New \\
\hline 16 & External energy input & $\begin{array}{c}\sum(\text { external input } \times \text { energy equivalent }) / \text { hectare } \\
(\mathrm{GJ} / \mathrm{ha}) \text { — quantitative }\end{array}$ & DEXi-Biort \\
\hline 17 & No-renewable input dependence & external input/total input (\%)—quantitative & DEXi-Biort \\
\hline 18 & Reuse input & input autoproduced/total input (\%) —quantitative & DEXi-Biort \\
\hline 19 & Fertilizer C/N & carbon/ Nitrogen-quantitative & DEXi-Biort \\
\hline 20 & On-farm fertilizers & -qualitative & DEXi-Biort \\
\hline 21 & Cause of phytosanitary treatment & -qualitative & DEXi-Biort \\
\hline 22 & Impact of phytosanitary treatment & -qualitative & DEXi-Biort \\
\hline 23 & Approach of phytosanitary treatment & -qualitative & DEXi-Biort \\
\hline 24 & Crop rotation & -qualitative & New \\
\hline 25 & Strip cultivation with agro-ecological function & -qualitative & New \\
\hline 26 & Floristic abundance & satellite tree & MASC \\
\hline 27 & Floristic diversity & satellite tree & MASC \\
\hline 28 & Macrofauna preservation & satellite tree & MASC \\
\hline 29 & Flying insects preservation & satellite tree & MASC \\
\hline 30 & Microrganism preservation & satellite tree & MASC \\
\hline
\end{tabular}




\begin{tabular}{|c|c|c|c|c|c|c|c|c|}
\hline Basic attributes & Weight $\%$ & $\begin{array}{c}\text { Aggregate } \\
\text { attributes }\end{array}$ & Weight $\%$ & $\begin{array}{c}\text { Aggregate } \\
\text { attributes }\end{array}$ & Weight $\%$ & $\begin{array}{c}\text { Aggregate } \\
\text { attributes }\end{array}$ & Weight $\%$ & $\begin{array}{c}\text { Overall } \\
\text { sustainability }\end{array}$ \\
\hline Insect pests and diseases & \multicolumn{3}{|c|}{50} & \multirow{2}{*}{ control pests } & \multirow{2}{*}{33} & \multirow{8}{*}{$\begin{array}{c}\text { production } \\
\text { capacity }\end{array}$} & \multirow{8}{*}{25} & \\
\hline Weeds & & 50 & & & & & & \\
\hline Soil structure & & 25 & & \multirow{4}{*}{$\begin{array}{l}\text { physico chemical } \\
\text { fertility }\end{array}$} & \multirow{4}{*}{33} & & & \\
\hline$P$ and $K$ Fertility & & 25 & & & & & & \\
\hline Acido basic balance & & 25 & & & & & & \\
\hline $\mathrm{N}$ balance & \multicolumn{3}{|c|}{25} & & & & & \\
\hline Production quantity & \multicolumn{3}{|c|}{60} & \multirow{2}{*}{ production } & \multirow{2}{*}{33} & & & \\
\hline Production quality & \multicolumn{3}{|c|}{40} & & & & & \\
\hline Water consumption & \multicolumn{3}{|c|}{33} & \multirow{3}{*}{ water } & \multirow{3}{*}{50} & \multirow{7}{*}{$\begin{array}{c}\text { soil and water } \\
\text { preservation }\end{array}$} & \multirow{7}{*}{25} & \\
\hline Groundwater utilization & & 33 & & & & & & \\
\hline Irrigation technology & & 33 & & & & & & \\
\hline Tillage diversification & 50 & & & \multirow{4}{*}{ soil } & \multirow{4}{*}{50} & & & \\
\hline Tillage typology and depth & 50 & soil treatments & 32 & & & & & \\
\hline Soil erosion control & \multicolumn{3}{|c|}{32} & & & & & $\Xi$ \\
\hline Organic matter balance & \multirow{2}{*}{\multicolumn{3}{|c|}{$\frac{37}{40}$}} & & & & & है \\
\hline External energy input & & & & \multirow{3}{*}{ energy } & \multirow{3}{*}{33} & \multirow{8}{*}{$\begin{array}{l}\text { resources } \\
\text { preservation }\end{array}$} & \multirow{8}{*}{25} & $\Xi$ \\
\hline No renewable input dependence & \multicolumn{3}{|c|}{30} & & & & & 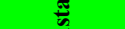 \\
\hline Reuse input & \multicolumn{3}{|c|}{$\frac{30}{70}$} & & & & & \\
\hline Fertilizer $\mathrm{C} / \mathrm{N}$ & & 70 & & fertilization & 33 & & & \\
\hline On-farm fertilizers & \multicolumn{3}{|c|}{30} & 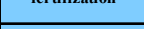 & (3) & & & \\
\hline Cause of phytos anitary treatment & & 30 & & & & & & \\
\hline Impact of phytosanitary treatment & & 40 & & management & 33 & & & \\
\hline Approach of phytosanitary treatment & & 30 & & & & & & \\
\hline Crop rotation & 60 & & & & & & & \\
\hline Strip cultivation with agroecological function & 40 & specific variability & 50 & flora & 50 & & & \\
\hline $\begin{array}{l}\text { Floristic aboundance } \\
\end{array}$ & 50 & & & & & biodiversity & & \\
\hline Floristic diversity & 50 & flora conservation & 50 & & & conservation & 25 & \\
\hline Macrofauna preservation & & 60 & & & 25 & & & \\
\hline Fying insects preservation & & 40 & & Iauna & 25 & & & \\
\hline Microrganism preservation & & 100 & & micro organism & 25 & & & \\
\hline $\begin{array}{l}\text { (low, medium low, medium high, } \\
\text { high)/(low,medium,high) }\end{array}$ & & $\begin{array}{l}\text { (low, medium low, } \\
\text { medium high, high) }\end{array}$ & & $\begin{array}{l}\text { (low, medium low, } \\
\text { medium high, high) }\end{array}$ & & $\begin{array}{l}\text { (low, medium } \\
\text { low, medium, } \\
\text { medium high, } \\
\text { high) }\end{array}$ & & $\begin{array}{l}\text { (very low, low, } \\
\text { medium } \\
\text { low,medium, } \\
\text { medium high, } \\
\text { high, very high) }\end{array}$ \\
\hline & & & SCALE & & & & & \\
\hline
\end{tabular}

Figure 3. New multi-criteria model (DEXi-met) decision tree. Different colors represent different attribute levels, i.e., 30 basic attributes (in yellow; light yellow if generated by satellite trees), aggregate attributes at different levels (orange and light blue), four nodal attributes (olive green) and overall sustainability (green). The numbers between attribute levels represent the default aggregation weights (expressed in \%). For each attribute level (basic, aggregate, and overall), the scale is shown at the bottom of the figure.

\subsection{Experimental Device Evaluation}

The data used to validate the DEXi-met model and evaluate the environmental sustainability of the two different crop management treatments (RC-ASC and NO-ASC) were collected during the 2016 cropping cycle of the above described MITIORG long-term field experiment. For this reason, this tool is specific for an organic vegetable cropping system, and is not suitable "as is" for conventional agriculture. To describe the output of the new multi-criteria decision model, the results of the overall environmental sustainability were extrapolated, along with four maximum aggregate attributes, sustainability, and the evaluation of all of the tree attributes, starting from the basic attributes.

The overall environmental sustainability of the tested cropping systems varied considering the two crop managements from "high", which was showed by RC-ASC, to "medium high", which was showed by NO-ASC (Figure 4).

As suggested by Canali et al. [6], the ASC introduction in sustainable organic farming systems represents a powerful tool for farmers to positively influence the agro-ecosystem, by promoting the whole soil-plant system equilibrium in space and time. Moreover, the same authors [23] pointed out that the introduction of the ASC termination by the roller crimper reduces the energy cost, compared with the traditional cover crops termination (green manure), thus increasing the economical sustainability of this practice. However, even if the ASC could have some other beneficial aspects, the DEXi-met model evaluated only environmental sustainability by giving a quantitative output to this important topic that should be taken into account. In particular, at the farming level, this result, and more specifically, the presence of ASC in crop rotation, could support the farmers in their choice 
of both the number of crops and the type of the agronomical practices [24]. Furthermore, since the introduction of ASC and their proper termination represent sustainable agricultural practices in organic farming, providing beneficial services for the agro-ecosystems, the results of DEXi-met could help policymakers understand and suggest new strategies for adaptation to climate change [25], due to the importance of sustainable agronomic practices in solving this issue.

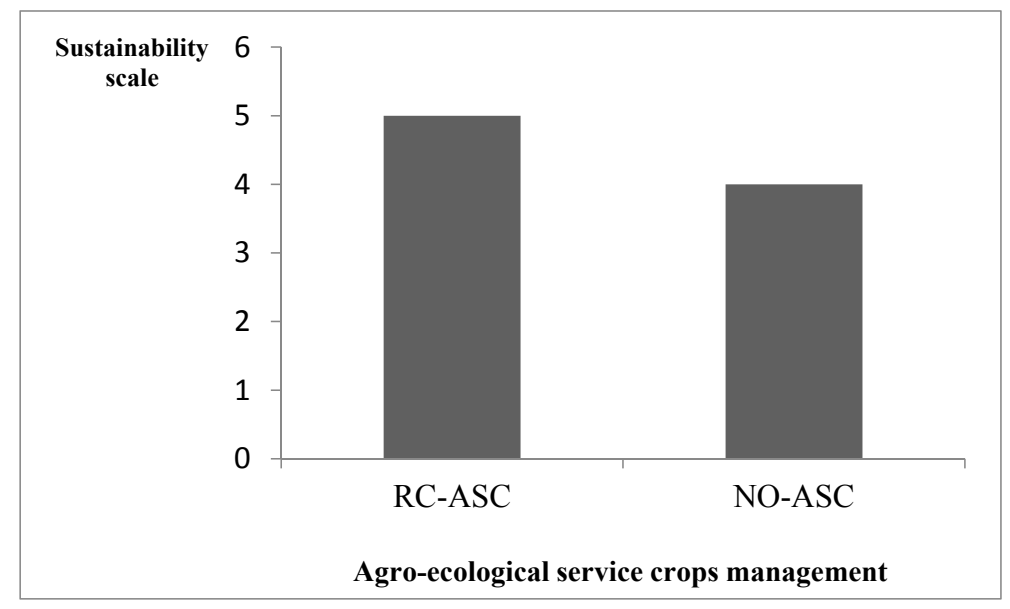

Figure 4. Comparison between the two crop managements: evaluation results of the multi-criteria decision model DEXi-met. Overall sustainability is defined as: very low $=0$, low $=1$, medium-low $=2$, medium $=3$, medium-high $=4$, high $=5$, very high $=6$ (RC-ASC $=$ agro-ecological service crops terminated by roller crimper; NO-ASC $=$ no agro-ecological service crops control).

The obtained result of the overall environmental sustainability can be explained by the scores of the nodal aggregate attributes of sustainability (Figure 5).

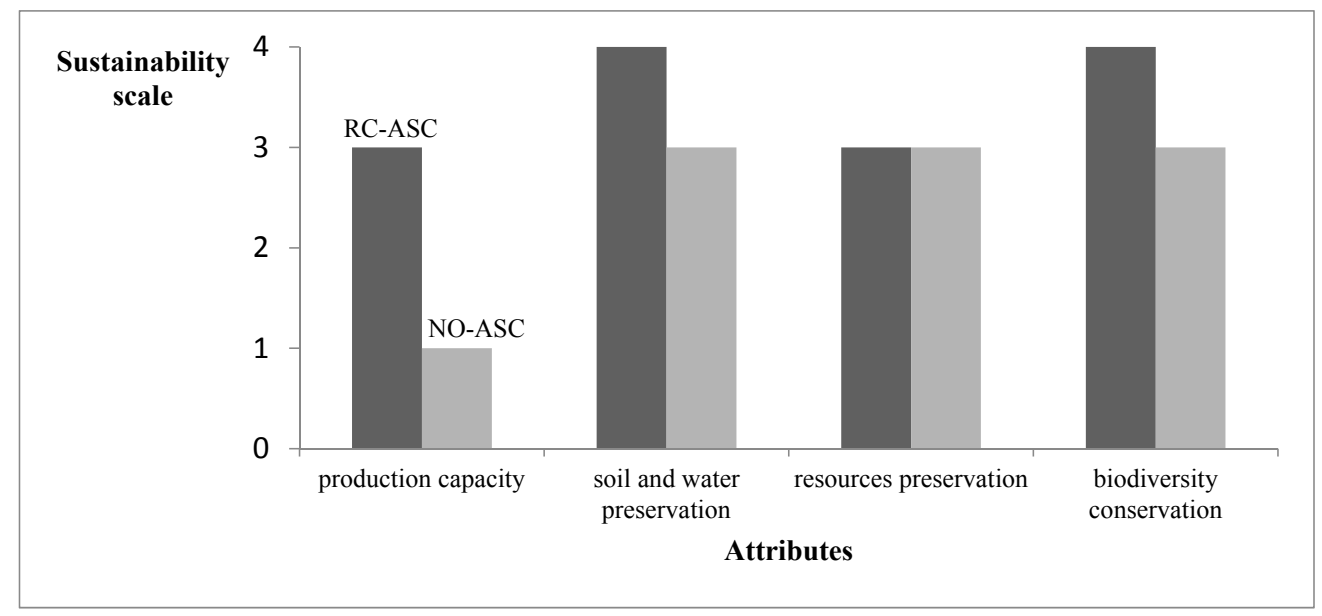

Figure 5. Production capacity, soil, and water preservation, resources preservation, and biodiversity conservation of the two different crop managements. Aggregate attributes sustainability is: $0=10 w$, 1 = medium low, 2 = medium 3 = medium high, $4=$ high $($ RC-ASC $=$ agro-ecological service crops terminated by roller crimper; NO-ASC $=$ no agro-ecological service crops control).

In particular, the higher result obtained by the RC-ASC crop management was because the DEXi-met output scored "high" for both soil and water preservation and biodiversity conservation aggregate attributes, compared with "medium high" for the NO-ASC crop management. Furthermore, the RC-ASC showed a higher value also for production capacity in respect to NO-ASC ("medium-high" and "medium", respectively), while the resources preservation aggregate attribute did not show any 
difference between the two crop managements (being "medium-high"). The results obtained by the application of the DEXi-met model confirm that the introduction of agro-ecological practices can increase the environmental sustainability of the cropping system at different levels. Furthermore, another research indicated that the use of organic amendments may be an option for carbon sequestration in soil in addition to the improvement of crop productivity [26]. This is particularly important, since it is well-known that the carbon sequestration in plant biomass has an important environmental impact, due to the role of $\mathrm{CO}_{2}$ in global climate change [27]. In the case of DEXi-met, the carbon sequestration was not directly measured in the model, but the indirect effect of both ASC termination and organic amendments (i.e., soil erosion control and increase in production quality and quantity) was measured.

Table 2 shows the evaluation results of the DEXi-met model for all of the attributes, as a comparison between the two crop managements (RC-ASC and NO-ASC).

Table 2. Evaluation results of the DEXi-met model, with comparisons between the two crop managements, from the overall environmental sustainability to the basic attributes (RC-ASC $=$ agro-ecological service crops terminated by roller crimper; NO-ASC = no agro-ecological service crops control).

\begin{tabular}{|c|c|c|c|}
\hline Attribute & RC-ASC & NO-ASC & \\
\hline Overall sustainability & high & medium high & Sustainable \\
\hline Production capacity & medium high & medium low & \\
\hline control of pests and diseases & medium high & medium low & \\
\hline insects and pests diseases & medium low & medium low & \\
\hline weeds & medium high & medium low & Not sustainabile \\
\hline physico-chimical fertility & medium high & medium low & \\
\hline soil structure & medium high & medium high & \\
\hline$P$ and $K$ fertility & medium low & medium low & \\
\hline acido basic balance & medium low & medium low & \\
\hline $\mathrm{N}$ balance (input/output) & high & low & \\
\hline production & medium high & medium low & \\
\hline production quantity & medium low & low & \\
\hline production quality & medium high & medium high & \\
\hline Soil and water preservation & high & medium high & \\
\hline water & high & high & \\
\hline water consumption & high & high & \\
\hline groundwater utilization & high & high & \\
\hline irrigation tecnology & high & high & \\
\hline soil & high & medium high & \\
\hline soil treatments & high & high & \\
\hline tillage diversification & high & high & \\
\hline tillage typology and depth & high & high & \\
\hline soil erosion control & high & medium low & \\
\hline organic matter balance & high & high & \\
\hline Resources preservation & medium high & medium high & \\
\hline energy & medium high & medium high & \\
\hline external energy input & high & medium & \\
\hline no-renewable input dependence & medium & high & \\
\hline reuse input & low & low & \\
\hline fertilization & medium low & medium low & \\
\hline fertilizers $\mathrm{C} / \mathrm{N}$ & high & high & \\
\hline on-farm production & low & low & \\
\hline phytosanitary management & high & high & \\
\hline cause of phytosanitary treatment & high & high & \\
\hline impact of phytosanitary treatment & high & high & \\
\hline approach of phytosanitary treatment & high & high & \\
\hline Biodiversity conservation & high & medium high & \\
\hline flora & medium high & medium high & \\
\hline specific variability & medium high & medium high & \\
\hline crop rotation & medium & medium & \\
\hline strip cultivation with agr.eco. function & medium & medium & \\
\hline flora conservation & medium high & medium high & \\
\hline floristic aboundance & medium low & medium high & \\
\hline floristic diversity & medium high & medium high & \\
\hline macro fauna conservation & high & medium high & \\
\hline macro fauna preservation & high & medium high & \\
\hline flying insect preservation & medium high & medium low & \\
\hline microrganism preservation & high & medium high & \\
\hline
\end{tabular}


The data are presented from the overall environmental sustainability to the values of the basic attributes carried out by the group of decision analysts and experts. The production capacity is generated from the attribute control of pests and diseases, physical-chemical fertility, and crop production. In the RC-ASC management, most of these attributes scored "high" or "medium-high", whereas in NO-ASC, the most frequent score was "medium-low". These differences were likely due to the mulching effect that occurred in the RC-ASC crop management, which can determine better weeds control [23], better N balance [28] and higher production than NO-ASC [6].

The results of the model are in agreement with the findings of Canali et al. [29] and Diacono et al. [30], who indicated that the ASC utilization is a viable option in Mediterranean conditions for organic farmers, which can also sustain the quantity and quality of production. Therefore, the output of this multi-criteria decision model is important to understand the ways of maximizing crop yield, increasing the efficiency of conservation agriculture practices at the same time. The soil and water preservation attributes showed no differences among water management options, while the attribute soil was "high" for RC-ASC and "medium high" for NO-ASC, due to a higher soil erosion control in RC-ASC, mainly deriving from the better soil cover during the high rainfall risk period. This outcome is in agreement with the findings reported by De Benedetto et al. [25]. The authors demonstrated that the ASC cover reduced soil losses, and consequently maintained the level of crop productivity, even after extreme rainfall events. This result is particularly important if we consider that the DEXi-met model was developed in a context of organic agriculture, in which it is difficult to find practices that generate differences. For example, the RC-ACS and NO-ASC had the same evaluation in organic matter balance (for both treatments was "high"), and therefore, this parameter may not be adopted to evaluate the efficiency of the tested agricultural practices. No differences were found in the nodal attributes of resources preservation, because the inputs (energy, fertilizer, and pesticides) were similar for the two crop managements. Finally, the DEXi-met output showed that RC-ASC was more sustainable than NO-ASC, due to a higher biodiversity conservation attribute ("high" and "medium-high", respectively). Similarly, Navarro-Mirò et al. [31] indicated that the presence of ASC with roller crimper termination enhances insect communities and pest regulation.

Although DEXi-met was tested in the same experimental field, and therefore with same pedo-climatic conditions and agronomic practices, the results showed differences between the two ASC managements that are detectable by the model, thus suggesting its good sensitivity to discriminate among practices. On the whole, the findings of this research indicated that the Dexi-met model, which was developed at the cropping system level, could give a new opportunity to quantify the environmental sustainability of different management procedures in organic vegetable production. The most important practical use of the model (by the farmers, stakeholders, or policymakers) will be to schedule sustainable agronomical practices. This is crucial under climate change conditions as in the study site, where frequent high-intensity rainfalls usually occur after a very dry summer and, together with climatic fluctuations, have been generally pointed out as the main climatic characteristic affecting the vulnerability of the Mediterranean basin to soil erosion. Thus, functionally integrated techniques are necessary in order to ensure the adaptation of horticultural systems to such extreme rainfall events.

\section{Conclusions}

In a context of climate change, it is extremely important for agricultural farms to obtain yields in a "sustainable way". The essential prerequisite for applying a more sustainable technique compared to another one is to know the impacts generated on the cropping system. The new multi-criteria DEXi-met model that was designed in this research could be useful for understanding the determinants of the environmental sustainability by disaggregating this 'difficult to understand concept' into smaller concept/components (attributes) that are easier to be evaluated. 
In particular, data from the MITIORG long-term field experiment enabled performing an in-depth evaluation of the potential of the new multi-attribute decision model. The most sustainable scenario was the one with the implementation of the principles of agro-ecology characterized by a greater diversification, which is obtained by adopting agro-ecological services crops in an organic vegetable cropping system.

Our proposed innovative modeling approach provides an easy method of decisional support to allow selecting different crop management strategies and assessesing the environmental sustainability of the cultivation systems. These findings might be taken into account in order to maximize crop yield, increase the efficiency of farming practices, and minimize the potential environmental impacts of agricultural activities. Further research should be aimed at testing different management practices on the evaluation of sustainability effects, also in different environmental conditions.

Author Contributions: Conceptualization, F.M., A.P. and M.D.; Methodology, A.P., F.M.; Writing-Original Draft Preparation, F.M., A.P. and M.D.; Writing-Review \& Editing, M.D.; Project Administration, F.M.

Funding: This research received no external funding.

Acknowledgments: This paper is a result of the AGROCAMBIO (Sistemi e tecniche AGROnomiche di adattamento ai CAMbiamenti climatici in sistemi agricoli BIOlogici) and RETIBIO (Attività di supporto nel settore dell'agricoltura biologica per il mantenimento dei dispositivi sperimentali di lungo termine e il rafforzamento delle reti di relazioni esistenti a livello nazionale e internazionale) research projects funded by the Organic Farming Office of the Italian Ministry of Agriculture.

Conflicts of Interest: The authors declare no conflict of interest.

\section{References}

1. IPCC. Climate Change: Mitigation of Climate Change. Contribution of Working Group I to the Fourth Assessment Report of the Intergovernmental Panel on Climate Change; Solomon, S., Qin, D., Manning, M., Chen, Z., Marquis, M., Averyt, K.B., Tignor, M., Miller, H.L., Eds.; Cambridge University Press: Cambridge, UK; New York, NY, USA, 2007; 996p.

2. Beddington, J.; Asaduzzaman, M.; Fernandez, A.; Clark, M.; Guillou, M.; Jahn, M.M.; Erda, L.; Mamo, T.; Bo, N.V.; Nobre, C.A.; et al. Achieving Food Security in the Face of Climate Change: Final Report from the Commission on Sustainable Agriculture and Climate Change; CGIAR: Copenhagen, Denmark, 2012; Available online: https:/ / ccafs.cgiar.org/publications/achieving-food-security-face-climate-change-summary-policymakers-commission\#.WpaI5ujOXIU (accessed on 10 April 2018).

3. IPCC. Climate Change: Impacts, Adaptations and Mitigation of Climate Change: Scientific-Technical Analyses. Contribution of Working Group II to the Second Assessment Report of the Intergovernmental Panel on Climate Change; Watson, R., Zinyowera, M.C., Moss, R.H., Dokken, D.J., Eds.; Cambridge University Press: Cambridge, UK; New York, NY, USA, 1996; 891p.

4. Ikerd, J.E. The need for a systems approach to sustainable agriculture. Agric. Ecosyst. Environ. 1993, 46, 147-160. [CrossRef]

5. IPCC. Climate Change: Mitigation of Climate Change. Contribution of Working Group III to the Fourth Assessment Report of the Intergovernmental Panel on Climate Change; Metz, B., Davidson, O.R., Bosch, P.R., Dave, R., Meyer, L.A., Eds.; Cambridge University Press: Cambridge, UK; New York, NY, USA, 2007; 852p.

6. Canali, S.; Diacono, M.; Campanelli, G.; Montemurro, F. Organic no till with roller crimpers: Agro-ecosystem services and applications in organic Mediterranean vegetable productions. Sustain. Agric. Res. 2015, 4, 66-75. [CrossRef]

7. Pope, J.; Annandale, D.; Morrison-Saunders, A. Conceptualising sustainability assessment. Environ. Impact Assess. Rev. 2004, 24, 595-616. [CrossRef]

8. Ness, B.; Urbel Piirsalu, E.; Anderberg, S.; Olsson, L. Categorising tools FOS sustainability assessment. Ecol. Econ. 2007, 60, 498-508. [CrossRef]

9. Van de Fliert, E.; Braun, A.R. Conceptualizing integrative, farmer participatory research for sustainable agriculture: From opportunities to impact. Agric. Hum. Values 2002, 19, 25-38. [CrossRef]

10. Gafsi, M.; Legagneux, B.; Nguyen, G.; Robin, P. Towards sustainable farming systems: Effectiveness and deficiency of the French procedure of sustainable agriculture. Agric. Syst. 2006, 90, 226-242. [CrossRef] 
11. Munda, G.; Nijkamp, P.; Rietveld, P. Qualitative multicriteria evaluation for environmental management. Ecol. Econ. 1994, 10, 97-112. [CrossRef]

12. Munda, G. Multiple Criteria Decision Analysis and Sustainable Development. Multiple Criteria Decision Analysis: State of the Art Surveys. International Series in Operations Research \& Management Science; Springer: New York, NY, USA, 2005; Volume 78. [CrossRef]

13. Craheix, D.; Bergez, J.E.; Angevin, F.; Bockstaller, C.; Bohanec, M.; Colomb, B.; Doré, T.; Fortino, G.; Guichard, L.; Pelzer, E.; et al. Guidelines to design models assessing agricultural sustainability, based upon feedbacks from the DEXi decision support system. Agron. Sustain. Dev. 2015, 35, 1431-1447. [CrossRef]

14. Chopin, P.; Tirolien, J.; Blazy, J.M. Ex-ante sustainability assessment of cleaner banana production Systems. J. Clean. Prod. 2016, 139, 15-24. [CrossRef]

15. Sadok, W.; Angevin, F.; Bergez, J.; Bockstaller, C.; Colomb, B.; Guichard, L.; Reau, R.; Messéan, A.; Doré, T. MASC, a qualitative multi-attribute decision model for ex ante assessment of the sustainability of cropping systems. Agron. Sustain. Dev. 2009, 29, 447-461. [CrossRef]

16. Bohanec, M. DEXi: Program for Multi-Criteria Decision Making, User's Manual, Version 5.00. IJS Report DP-11897; Jožef Stefan Institute: Ljubljana, Slovenia, 2015; Available online: http://kt.ijs.si/MarkoBohanec/DEXi/ html/DEXiDoc.htm (accessed on 5 January 2018).

17. Bohanec, M.; Žnidaršič, M.; Rajkovič, V.; Bratko, I.; Zupan, B. DEX Methodology: Three Decades of Qualitative Multi-Attribute Modelling. Informatica 2013, 37, 49-54.

18. Nikoloski, T.; Udovc², A.; Pavlovic $²$ M.; Rajkovic², U. Farm reorientation assessment model based on multi-criteria decision making. Comput. Electron. Agric. 2017, 140, 237-243. [CrossRef]

19. Diacono, M.; Fiore, A.; Farina, R.; Canali, S.; Di Bene, C.; Testani, E.; Montemurro, F. Combined agro-ecological strategies for adaptation of organic horticultural systems to climate change in Mediterranean environment. Ital. J. Agron. 2016, 11, 85-91. [CrossRef]

20. Taškova, K.; Stojanova, D.; Bohanec, M.; Džeroski, S. A Qualitative decision-support model for evaluating researchers. Informatica 2007, 3, 479-486.

21. Moonen, C.; Bigongiali, F.; Barberi, P.; Ortolani, L.; Colombo, L.; Vazzana, C.; Lazzerini, G.; Moschini, V. Manuale di DEXI-BIOrt uno strumento per la Valutazione Agro-Ambientale Delle Aziende Orticole Biologiche Italiane, 2012. (In Italian). Available online: http://hdl.handle.net/2158/960388 (accessed on 15 December 2017).

22. Bohanec, M.; Messéan, A.; Scatasta, S.; Angevin, F.; Griffiths, B.; Krogh, P.H.; Žnidaršič, M.; Džeroski, S. A qualitative multi-attribute model for economic and ecological assessment of genetically modified crops. Ecol. Model. 2008, 215, 247-261. [CrossRef]

23. Ciaccia, C.; Canali, S.; Campanelli, G.; Testani, E.; Montemurro, F.; Leteo, F.; Delate, K. Effect of roller-crimper technology on weed management in organic zucchini production in a Mediterranean climate zone. Renew. Agric. Food Syst. 2016, 31, 111-121. [CrossRef]

24. Montemurro, F.; Fiore, A.; Campanelli, G.; Tittarelli, F.; Ledda, L.; Canali, S. Organic fertilization, green manure, and vetch mulch to improve organic zucchini yield and quality. HortScience 2013, 48, 1027-1033.

25. De Benedetto, D.; Montemurro, F.; Diacono, M. Impacts of Agro-Ecological Practices on Soil Losses and Cash Crop Yield. Agriculture 2017, 7, 103. [CrossRef]

26. Pergola, M.; Persiani, A.; Pastore, V.; Palese, A.M.; Arous, A.; Celano, G. A comprehensive Life Cycle Assessment (LCA) of three apricot orchard systems located in Metapontino area (Southern Italy). J. Clean. Prod. 2017, 142, 4059-4407. [CrossRef]

27. Arous, A. Management of Soil Organic Matter and Carbon Storage in Mediterranean Fruit Orchards. International PhD "BioEcosystems and Biotechnoly". Ph.D. Thesis, University of Basilicata, Basilicata, Italy, 2015.

28. Montemurro, F.; Diacono, M.; Ciaccia, C.; Campanelli, G.; Tittarelli, F.; Leteo, F.; Canali, S. Effectiveness of living mulch strategies for winter organic cauliflower (Brassica oleracea L. var. botrytis) production in Central and Southern Italy. Renew. Agric. Food Syst. 2017, 32, 263-272. [CrossRef]

29. Canali, S.; Campanelli, G.; Ciaccia, C.; Leteo, F.; Testani, E.; Montemurro, F. Conservation tillage strategy based on the roller crimper technology for weed control in Mediterranean vegetable organic cropping systems. Eur. J. Agron. 2013, 50, 11-18. [CrossRef] 
30. Diacono, M.; Persiani, A.; Fiore, A.; Montemurro, F.; Canali, S. Agro-Ecology for Potential Adaptation of Horticultural Systems to Climate Change: Agronomic and Energetic Performance Evaluation. Agronomy 2017, 7, 35. [CrossRef]

31. Navarro-Miró, D.; Caballero-López, B.; Blanco-Moreno, J.M.; Pérez, A.; Depalo, L.; Masetti, A.; Burgio, G.; Canali, S.; Sans, F.X. Agro-ecological Service Crops with roller crimper termination enhance ground-dwelling predator communities and pest regulation. In Proceedings of the 5th ISOFAR Scientific Conference “Innovative Research for Organic 3.0" 19th Organic World Congress, New Dehli, India, 9-11 November 2017. 